\title{
¿PUEDEN LOS ANIMALES SER TITULARES DE DERECHOS? ALGUNOS ARGUMENTOS DESDE UNA TEORÍA GARANTISTA DEL DERECHO
}

\author{
JosÉ ANTONIO GARCÍA SAEZ \\ Becario FPU del Ministerio de Educación \\ Institut de Drets Humans - Universitat de València \\ jose.a.garcia@uv.es
}

Recibido: 9 de mayo de 2012 / Aceptado: 19 de julio 2012

\begin{abstract}
RESUMEN: Este trabajo es el resultado de una preocupada reflexión acerca de la situación ambiental que toma las controversias a propósito de los derechos de los animales como punto de partida. En primer lugar se realizan algunas consideraciones preliminares acerca de la mirada antropocéntrica que impregna la cultura jurídica en la que a diario se mueven los juristas. A continuación se analizan seis argumentos que con frecuencia presentan quienes, desde diferentes perspectivas, consideran que los animales no pueden o no deben ser titulares de derechos. Se pretende demostrar que desde el punto de vista de la teoría del Derecho tales argumentos no serían suficientes para afirmar que los animales no puedan ser titulares de derechos subjetivos. Otra cuestión más compleja es si la titularidad de derechos es la fórmula más adecuada para proteger no solo a los animales, sino al conjunto de la naturaleza. Sobre ello se apuntan dos propuestas de convivencia inspiradas en la teoría del garantismo jurídico: una de carácter teórico general y otra concreta referida al modelo alimentario.
\end{abstract}

RESUM: Aquest treball és el resultat d'una preocupada reflexió sobre la situació ambiental que pren les controvèrsies a propòsit dels drets dels animals com a punt de partida. En primer lloc es realitzen algunes consideracions preliminars sobre la mirada antropocèntrica que impregna la cultura jurídica en la qual diàriament es mouen els juristes. A continuació s'analitzen sis arguments que amb freqüència han estat presentats aquells que, des de diferents perspectives, consideren que els animals no 
poden o no han de ser titulars de drets. Es pretén demostrar que, des del punt de vista de la Teoria del Dret, eixos arguments no serien suficients per afirmar que els animals no puguin ser titulars de drets subjectius. Una altra qüestió més complexa és si la titularitat de drets és la fórmula més adequada per protegir no només als animals, sinó al conjunt de la naturalesa. Sobre això s'apunten dues propostes de convivència inspirades en la teoria del garantisme jurídic: una de caràcter teòric general i una altra concreta referida al model alimentari.

\begin{abstract}
This paper is the result of a committed reflection on the environmental situation, taking disputes about the rights of animals as a starting point. First, some preliminary considerations about the anthropocentric view that permeates the hegemonic legal culture are made. Afterwards six arguments are discussed. They have often been presented by those who, from different perspectives, have believed that animals cannot or should not have rights. The discussion aims to demonstrate that such arguments would not be sufficient to state that animals cannot be holders of subjective rights, arguing from the point of view of legal theory. Different and more complex is questioning if rights are the best formula to protect not only animals, but environment broadly. On this topic, are made two proposals of coexistence inspired by the garantist theory: a general one and a specific one referring to alimentary model.
\end{abstract}

PALABRAS CLAVE: Derechos de los animales — teoría del Derecho - garantismo - justicia global.

PARAULES CLAU: Drets dels animals - teoria del Dret - garantisme - justícia global.

KEYWORDS: Animal rights — legal theory — garantism — global justice. 
Sumario: I. Superar la mirada antropocéntrica. II. Argumentos a favor y en contra desde la teoría del Derecho. 1. Argumento 1: reductio ad absurdum. 2. Argumento 2: la imposible titularidad de deberes. 3. Argumento 3: el imposible ejercicio de los derechos. 4. Argumento 4: bienes jurídicos protegidos. 5. Argumento 5: la funcionalidad del Derecho. 6. Argumento 6: la teoría de los círculos concéntricos. III. Dos propuestas de convivencia garantista. 1. Propuesta de desarrollo de la teoría garantista. 2. Propuesta de modelo alimentario. IV. Bibliografía.

\section{SUPERAR LA MIRADA ANTROPOCÉNTRICA}

Prácticamente nadie cuestiona en la actualidad que los animales necesitan y merecen una mayor protección por parte del Derecho tanto a nivel estatal como a nivel internacional. Sin embargo, con frecuencia se encuentran voces que ponen en tela de juicio que los animales puedan ser titulares de derechos. El objetivo principal de este trabajo es analizar críticamente algunos de los argumentos utilizados por quienes defienden que no se puede o no se debe hablar de que los animales tengan derechos, así como las respuestas que se pueden proporcionar en el sentido contrario desde el punto de vista de la teoría del Derecho. En todo caso, cabe advertir que se trata de una discusión abierta y de unos argumentos que todavía se encuentran en fase de construcción. La intención de este trabajo, por lo tanto, dista de intentar proporcionar un catálogo acabado de argumentos. Únicamente se pretende reflexionar a propósito de si existen en la teoría jurídica obstáculos insuperables que desaconsejen o que hagan incorrecto en alguna medida hablar de derechos de los animales. Se trata sobre todo de estimular la imaginación jurídica, libre en lo posible de los prejuicios culturales que suelen dificultar la aproximación a este asunto.

No en balde, pensar en los derechos de los animales supone todo un reto para la ciencia jurídica. Implica pensar y repensar qué son el Derecho y los derechos. Invita a reflexionar en torno a qué son los derechos humanos e incluso en torno a qué significa ser humano. ¿Equivale automáticamente el término ser humano al término persona? Kelsen, por ejemplo, insistió en que "el objeto de la ciencia jurídica no es el hombre, sino la persona. Y la distinción de hombre y persona constituye uno de los

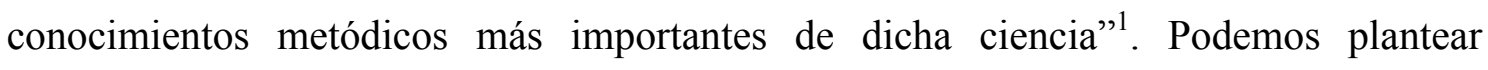
entonces si necesariamente el Derecho está limitado a aplicarse a los humanos o si puede ser aplicable a otras categorías de sujetos. En definitiva, pensar en los derechos de los animales es un reto apasionante que tal vez nos obligue a redefinir algunas de las categorías jurídicas que creíamos tener claras. El hecho de entrar a hablar en serio de

\footnotetext{
${ }^{1}$ KELSEN, H., Teoría general del Derecho, Coyocán, México, 2008, p. 82.
} 
derechos de los animales, o mejor, el no negarse a entrar en este ámbito, supone una sana actitud de cuestionamiento permanente de los parámetros jurídicos en los que nos movemos. Quizá después de haber entrado en profundidad lleguemos al mismo punto en el que estábamos; pero seguramente la experiencia no habrá sido en vano. Habrá servido, al menos, para clarificar las hipótesis epistemológicas de las que parte el sistema jurídico en el que operamos diariamente.

Se dice en ocasiones que la ideología es para las personas como el agua para los peces: no saben que nadan en ella. Por eso, considero importante tener bien presentes las consecuencias derivadas del hecho de que la cultura jurídica occidental en la que los juristas operan proviene directamente de una tradición de pensamiento judeocristiana que sitúa al ser humano en el centro de todas las cosas y considera — a diferencia de otras muchas cosmovisiones - que todo el resto de la naturaleza, animales incluidos, está a su servicio. Fue especialmente Agustín de Hipona quien introdujo en el siglo IV la idea de que los animales estaban literalmente creados para servir a las personas. Este postulado que sería adoptado más tarde por el emperador Justiniano y plasmado en sus importantes códigos legales ${ }^{2}$, de entre los cuales destaca el influyente Corpus Iuris Civilis.

El avance de la ciencia ha ido demostrando los numerosos errores en los que ha incurrido la religión, particularmente la católica, a lo largo de la historia. La Iglesia se equivocó al afirmar que la Tierra era plana. Se equivocó al afirmar que el ser humano no procedía evolutivamente de los primates, ignorando la existencia de un continuum biológico. Se equivocó al pensar que la mujer procedía de una costilla del hombre y era, por lo tanto, su subordinada. Se equivocó al apoyar algunas de las más atroces dictaduras del siglo XX. Probablemente se equivoque también al afirmar todavía la existencia de Dios y seguramente se equivoca al pensar aún que el ser humano es el centro del universo y que el resto de especies que comparten el mundo con él están simplemente a su servicio.

Esa visión antropocéntrica del mundo sin duda influyó de manera determinante en las concepciones filosóficas más influyentes en Occidente. Baste simplemente recordar de pasada los ejemplos de Descartes, quien consideraba a los animales como máquinas sin alma, y de Kant, quien negó que tuviéramos deber directo alguno hacia los animales al

\footnotetext{
${ }^{2}$ WISE, S. M., “Animal Rights, One Step at a Time”, en Nussbaum, M., Sustein Cass, R. (eds.), Animal rights: Current Debates and New Directions, Oxford University Press, Oxford, 2004, pp. 19-41.
} 
considerarlos como medios al servicio de un fin que es el ser humano. Por supuesto, la mirada antropocéntrica también determinó la forma de concebir el mundo del Derecho, que únicamente ha considerado como sujetos de dignidad — esto es, como personas - a aquellos seres dotados teóricamente de capacidad de razón y de elección moral. Por ese motivo, todavía hoy se considera un pleonasmo hablar de dignidad humana, como ha señalado De Lucas $^{3}$ siguiendo a Singer. Sin embargo, esa concepción jurídica que solo es capaz de asociar la dignidad con lo humano es algo, insisto, puramente cultural y, por lo tanto, superable. Una buena muestra de ello puede ser una sentencia del Tribunal Superior de Kerala (India) del año 2000 que dice textualmente: "Aunque no sean Homo sapiens, son también seres que tienen derecho a una existencia digna y a un trato humano sin crueldad ni tortura [...]. Si los seres humanos tienen derechos fundamentales, ¿por qué no los animales?”4.

La filosofía utilitarista ha sido, sin duda, la que más ha contribuido a la superación progresiva de esa mirada antropocéntrica y a la toma en consideración de los intereses de los animales desde el punto de vista moral. A Jeremy Bentham le corresponde el honor de empezar a hablar de una mayor protección de los animales en atención a su capacidad de sufrir. Es de sobra conocido entre los defensores de los derechos de los animales el archicitado fragmento de su obra de $1789^{5}$ que dice:

\begin{abstract}
"Quizá un día se llegue a reconocer que el número de patas, la vellosidad de la piel o la terminación del os sacrum son razones igualmente insuficientes para dejar abandonado a su mismo destino a un ser sensible. ¿Qué ha de ser, si no, lo que trace el límite insuperable? ¿Es la facultad de la razón o quizá la del discurso? Pero un caballo o un perro adulto es, más allá de toda comparación, un animal más racional y con el cual es más posible comunicarse que con un niño de un día, de una semana o incluso de un mes. Y aun suponiendo que fuese de otra manera, ¿qué significaría eso? La cuestión no es si pueden razonar o si pueden hablar, sino ¿pueden sufrir?".
\end{abstract}

\footnotetext{
${ }^{3}$ DE LUCAS, J., "En el bicentenario de Darwin. ¿Derechos de los animales no humanos? La barrera de la | dignidad", en Teoría y Derecho, núm. 6, 2009, pp. 6-19.

${ }^{4}$ Sentencia Nair v. Union of India del Tribunal Superior de Kerala, núm. 155/1999, de junio de 2000. Citada en NUSSBAUM, M., Las fronteras de la justicia. Consideraciones sobre la exclusión, Paidós, Barcelona, 2007, p. 321.

${ }^{5}$ BENTHAM, J., Introduction to the Principles of Morals and Legislation (1781), Adamant Media Corporation, 2005, pp. 310-311.
} 
Con Bentham se empieza a considerar de esta manera la capacidad de sentir como un criterio moralmente relevante. Posteriormente, en el siglo XIX puede destacarse el pensamiento de Henry S. Salt, en particular la obra Los derechos de los animales, publicada en 1892. En ella se inspirará Peter Singer en el siglo XX (Animal Liberation, 1975), aunque su enfoque esté basado, más que en la reivindicación de los derechos de los animales, en el respeto hacia sus intereses. Existen otros muchos, pero creo que estos tres autores son un buen exponente de la filosofía utilitarista según la cual el fín último de la moral sería la optimización de la felicidad que hay en el mundo y, en consecuencia, el objetivo principal del Derecho sería proteger unos intereses, cualquiera que sea el sujeto al que pertenezcan estos intereses y la especie a la que pertenezca este sujeto. Así pues, según esta concepción utilitarista, será igual de ilícito hacer sufrir a un animal que a un ser humano.

El enfoque neoutilitarista representado por Singer no ha sido el único que ha abordado el interrogante acerca de si a los animales deben reconocérseles derechos. Puede destacarse también el enfoque neokantiano representado por Tom Regan, quien ha considerado a los animales como seres dotados de un valor intrínseco que les haría merecedores de un determinado respeto. Sea porque los animales tienen capacidad de sentir, sea porque constituyen un valor en sí mismos, lo cierto es que el hecho de que el comportamiento de los seres humanos pueda interferir en la existencia de esos otros seres con los que comparten el planeta convierte el asunto en una cuestión de justicia ${ }^{6}$. Y, superados los condicionamientos culturales, no parece existir ningún motivo válido para restringir una cuestión de justicia al ámbito de lo estrictamente humano.

\section{ARGUMENTOS A FAVOR Y EN CONTRA DESDE LA TEORÍA DEL DERECHO}

Realizada esta breve introducción, tomaré ahora seis argumentos que suelen emplearse por quienes piensan que por motivos jurídicos no puede o no debe hablarse de derechos de los animales, e iré comentándolos en algunos casos sobre la base de los argumentos apuntados por quienes abogan por la necesidad de hablar de derechos de los animales y

\footnotetext{
${ }^{6}$ Vid. DE LORA, P., Justicia para los animales. La ética más allá de la humanidad, Alianza, Madrid, 2003.
} 
en otros casos a partir de una reflexión propia; siempre desde la perspectiva de la teoría jurídica.

\section{Argumento 1: reductio ad absurdum}

Son frecuentes los argumentos que pretenden reducir al absurdo las reivindicaciones de quienes defienden los derechos de los animales, poniendo ejemplos inviables como un chimpancé votando en las elecciones municipales o un caballo de carreras cobrando una pensión de jubilación. Pero estos argumentos en ningún caso están justificados y más que reducciones al absurdo acaban siendo argumentos absurdos. Nunca se han reivindicado derechos humanos para los animales: los derechos humanos están hechos para los humanos y no para los animales, los cuales tendrían derechos en función de sus diferentes características. Los derechos que se exigen para los animales han sido siempre derechos acordes a las diferentes naturalezas y capacidades de cada especie. Los derechos no tienen sentido sino para satisfacer necesidades ${ }^{7}$ y para ello precisamente surgen. Por ello, cuando se habla de derechos de los animales, quizá se debería aclarar que lo fundamental no es hablar de derechos de los animales en abstracto, sino determinar qué derechos y para qué animales. Sin cuestionar su igual valor como seres vivos, cualquiera puede imaginar que no tendrán las mismas necesidades un gran primate que un gusano de seda y, en consecuencia, no necesitarán los mismos derechos. A efectos expositivos, tomaré la triple diferenciación en la atribución de derechos que propone Riechmann ${ }^{8}$ :

a) En primer lugar, existiría un derecho animal básico a no ser torturado ni tratado con crueldad, del cual serían titulares todos aquellos animales que tuvieran la capacidad de experimentar dolor, por muy sencillos que fueran orgánicamente. En este punto coincidirían las posturas regulacionistas o bienestaristas (animal welfare) con las abolicionistas (animal rights). Es significativo el paralelismo que se puede establecer con los derechos humanos: según todas las normas internacionales de derechos humanos, el único derecho humano de carácter absoluto (que no admite excepciones o,

\footnotetext{
${ }^{7}$ Vid. AÑÓN ROIG, M. J., Necesidades y derechos: un ensayo de fundamentación, Centro de Estudios Constitucionales, Madrid, 1994.

${ }^{8}$ RIECHMANN, J., “La dimensión jurídica: ¿derechos para los animales?”, en Mosterín, J. y Riechmann, J., Animales y ciudadanos. Indagación sobre el lugar de los animales en la moral y el derecho de las sociedades industrializadas, Talasa, Madrid, 1995, p. 207.
} 
al menos, no las admitía hasta el 11 de septiembre de $2001^{9}$ ) es, junto con la prohibición de la esclavitud, la prohibición de la tortura. En ningún caso está justificado infligir dolor y de esta premisa puede considerarse que parten el resto de derechos fundamentales ${ }^{10}$ como instrumentos básicamente orientados a excluir o reducir el dolor o, más ampliamente, cualquier tipo de sufrimiento.

b) Un segundo escalón de derechos estaría compuesto por el derecho a la libertad, que se reivindicaría para aquellos animales que sufren perturbaciones graves cuando están sometidos a una falta de movilidad o de libertad deambulatoria, como podrían ser los mamíferos o ciertos tipos de aves. Está comprobado por los científicos que, si un águila es encerrada en una jaula, sufre un gran estrés que incluso le puede causar la muerte; en cambio, en nada parecen estar sufriendo los gusanos de seda que un niño mantiene retenidos en una caja de zapatos y a los que alimenta con hojas de morera.

c) En último lugar, se reclamaría el derecho a la vida únicamente para los animales denominados cuasi personas. Dentro de esta categoría se incluirían básicamente los grandes primates. Como sobradamente han demostrado las investigaciones del Proyecto Gran Simio ${ }^{11}$, estos grandes primates presentan un elevado nivel de autoconciencia y de conciencia del otro, un sentido desarrollado del tiempo y una continuidad biográfica. Con estas características, son capaces de tener un proyecto de vida que se puede ver frustrado con su muerte y pueden experimentar un intenso dolor por la pérdida de un pariente. La vida en sí es algo valioso para ellos y, por ese motivo, algo que debería ser susceptible de respeto y protección.

Así, según esta propuesta de clasificación, los únicos derechos que se piden para los animales son aquellos que los animales necesitan en función de su diferente naturaleza y capacidades. Como se ha dicho antes, nunca se han pedido seriamente derechos humanos para los no humanos, ni menos aún se ha intentado ignorar las innegables diferencias que separan a la especie humana del resto de especies. Ahora bien, el reconocimiento de estas diferencias no tendría por qué implicar necesariamente una desigual valoración de ellas para el ordenamiento jurídico, sino que se podrían incluir

\footnotetext{
${ }^{9}$ Sobre la problemática de la vuelta de la tortura, puede verse una buena síntesis en LA TORRE, M., “Teoría del Derecho de la tortura”, en Derechos y Libertades, núm. 17, Época II, junio 2007, pp. 71-87.

10 FERRAJOLI, L., "Derecho y dolor", en Ferrajoli, L., Democracia y garantismo, edición de M. Carbonell, Trotta, Madrid, 2008, pp. 123-131.

$11<$ www.proyectogransimio.org $>$.
} 
en un modelo de igual valoración jurídica de las diferencias como el que ha teorizado, entre otros, Ferrajoli respecto del Estado constitucional de derecho ${ }^{12}$.

Antes de pasar al siguiente argumento, debe mencionarse que el atender a la naturaleza de las diferentes especies a la hora de atribuir derechos a los animales no implica que sea la especie en su conjunto a quien se atribuirían los derechos. Los titulares de esos derechos serían los individuos (cada animal), no las especies. Las especies pueden ser lo importante para la biología o para el mantenimiento del equilibrio de los ecosistemas, pero son seguramente irrelevantes a efectos morales ${ }^{13}$. Es cada individuo por separado el que sufre dolores o privaciones; así que, como ocurre con los derechos humanos, sería cada individuo y no la especie en su conjunto quien debería ser titular de derechos.

\section{Argumento 2: la imposible titularidad de deberes}

Otro conocido argumento, este ya con un poco más de fundamento, es aquel que afirma que la titularidad de un derecho siempre conlleva la titularidad de un deber. Se puede pensar, por ejemplo, que, en principio, el contenido mínimo del derecho a la vida incluiría el deber de no matar. Sin embargo, no podemos imaginar que una orca cometa un asesinato cuando mata una foca para alimentarse. A la orca no le interesa el valor que pueda tener la vida de la foca ni puede comprender que cometería un delito en el caso de que el hecho de matar una foca hubiera sido tipificado en un código penal. Sobre ello se incidirá en el argumento cuarto. Lo importante aquí es destacar que los animales no son agentes morales y que, por lo tanto, no pueden ser sujetos de deberes. Una buena muestra de ello es el artículo 1.905 del Código Civil español, que atribuye a los dueños de los animales la responsabilidad por los daños que estos hubieran podido causar: "el poseedor de un animal, o el que se sirve de él, es responsable de los perjuicios que causare, aunque se le escape o extravíe".

Este argumento por sí solo no significa que los animales no puedan ser titulares de derechos. Por ese motivo, los defensores de los derechos de los animales alegan en este punto, y con razón, que también los niños pequeños o los humanos con deficiencias psíquicas profundas son incapaces de asumir las consecuencias de lo que significa la

\footnotetext{
${ }^{12}$ FERRAJOLI, L., Derechos y garantías. La ley del más débil, Ed. Trotta, Madrid, 2006; en especial, cap. III, "Igualdad y diferencia”, pp.73-96.

${ }^{13}$ NUSSBAUM, M., Las fronteras de la justicia... cit., p. 352 y ss.
} 
titularidad de un deber y, sin embargo, no se cuestiona su capacidad para ser titulares de derechos. De ese modo, si bien puede admitirse que los animales no son agentes morales, sí puede considerarse, junto a Regan ${ }^{14}$, que serían pacientes morales; es decir, sujetos merecedores de, al menos, una cierta consideración moral susceptible en principio de ser traducida al lenguaje de los derechos.

\section{Argumento 3: el imposible ejercicio de los derechos}

Al tercer argumento, que consiste en que los animales no podrían tener derechos porque no tienen la capacidad jurídica para reivindicarlos, se le puede dar una respuesta parecida a la anterior. Se alega que si un animal no tiene capacidad para actuar ante un tribunal para reivindicar la satisfacción de su derecho, no puede decirse que tenga realmente un derecho. Frente a ello puede replicarse que lo característico de un derecho no es que su titular pueda reclamarlo, sino que algún sujeto con capacidad jurídica de obrar pueda reclamarlo en beneficio del titular. De nuevo, tampoco los niños o los discapacitados mentales tienen capacidad plena de obrar ni de intervenir en un juicio y, sin embargo, las leyes de enjuiciamiento prevén diferentes figuras que se encargan de su representación procesal y de la protección de sus intereses.

Para justificar estas dos últimas réplicas, quienes abogan por los derechos de los animales acuden recurrentemente al concepto de derecho subjetivo de Hans Kelsen, para quien la figura del derecho subjetivo es solo una muletilla jurídica, un concepto auxiliar del conocimiento jurídico, pues lo que importa en realidad para el Derecho son las obligaciones y no los derechos subjetivos ${ }^{15}$. Es decir, uno solo tendría un derecho en

\footnotetext{
${ }^{14}$ REGAN, T., The Case for Animal Rights, University of California Press, 2004 [1983], pp. 151 y ss.

${ }^{15}$ Cabe aclarar, sin embargo, que esta teoría se considera en buena parte superada por numerosos juristas positivistas actuales. Paradigmáticamente, Ferrajoli considera que la posición de Kelsen supone confundir los derechos con sus garantías: "Una confusión de este tipo entre derechos y garantías, además de anular una buena parte de las más importantes conquistas del constitucionalismo del siglo XX, contradice, a mi juicio, la tesis de la naturaleza positiva - o nomodinámica, en el léxico kelseniano- del Derecho moderno. Al contrario que los sistemas que Hans Kelsen llama nomoestáticos, como la moral y el Derecho natural, en los sistemas nomodinámicos o positivos la existencia o inexistencia de las normas que disponen obligaciones, prohibiciones o derechos subjetivos no se deducen de la existencia de otras normas, sino que son 'puestas' [...] por los correspondientes actos de producción. Resulta, por tanto, perfectamente posible que, dado un derecho subjetivo como consecuencia de una norma que lo prevé, no existan hasta tanto no se produzcan - aunque debieran existir y, por lo tanto, ser producidas - ni las normas primarias que establecen la obligación o la prohibición correspondientes [...] ni las normas secundarias que disciplinan la persecución de las violaciones de unos y otros". FERRAJOLI, L., “Garantías", en Democracia y garantismo... cit., p. 73.
} 
la medida en que los demás tengan obligaciones respecto a él ${ }^{16}$. Desde una perspectiva positivista, por consiguiente, lo que realmente se necesita para afirmar que existe un derecho subjetivo es que este haya sido atribuido a algún sujeto mediante el Derecho objetivo, estableciendo el correspondiente deber jurídico de acción o de abstención. Kelsen hace hincapié en la incorrecta separación entre derechos y deberes que los iusnaturalistas establecen cuando hablan de derechos subjetivos, y afirma: "[...] la función esencial del Derecho (no sólo su función primaria) es el deber jurídico [...]. El derecho de uno no es sino la consecuencia del deber de otro; y ni siquiera la consecuencia necesaria” ${ }^{\prime 17}$. Así, incluso podría pensarse en un ordenamiento jurídico sin derechos subjetivos, aunque jamás podría imaginarse un ordenamiento jurídico, "y aun una simple norma de Derecho" ${ }^{\prime \prime}$, sin deberes jurídicos.

De esta forma, siguiendo la teoría pura de Kelsen, al ser el deber y no el derecho subjetivo lo fundamental, las objeciones formuladas en contra de los derechos de los animales podrían valer exactamente igual en contra de los derechos humanos. Por eso, podría responderse, como dice Salt al principio de su libro Los derechos de los animales: “¿Tienen derechos los animales inferiores? Sin duda, si es que los tienen los seres humanos"19. Si los niños y los discapacitados mentales pueden ser titulares de derechos aun sin ser titulares de deberes, también los animales podrían serlo.

Ahora bien, este argumento sería suficiente para afirmar que se puede hablar de derechos de los animales, pero a mi juicio sería todavía insuficiente para justificar que los animales deban tener derechos. En otras palabras, llegados a este punto me parece que ya habrían algunas razones de peso para empezar a considerar que se puede hablar de derechos de los animales sin demasiados problemas de índole teórico-jurídica. Otro problema que va más allá es si se debe. Es decir, si el atribuir derechos subjetivos a los animales es una condición necesaria para preservar no solo su existencia, sino también la dignidad que en justicia merecen.

\footnotetext{
${ }^{16}$ Por poner dos ejemplos, vid. H. KELSEN, Teoría Pura del Derecho. Introducción a la problemática cientifica del Derecho, Losada, Buenos Aires, 1941, pp. 72-73; y también H. KELSEN, Teoría General del Estado, Coyoacán, México D. F., 2008, p. 74.

${ }^{17}$ H. KELSEN, Teoría General... cit., p. 79.

${ }^{18}$ Ibídem.

${ }^{19}$ SALT, H. S., Los derechos de los animales, Los libros de la Catarata, Madrid, 1999, p. 29.
} 


\section{Argumento 4: bienes jurídicos protegidos}

A ese respecto merece la pena mencionar el argumento acerca del bien jurídico protegido. Se afirma que para proteger a los animales no es imprescindible reconocerles derechos, sino que bastaría considerarlos como bienes jurídicos a proteger. Se puede proteger perfectamente, por ejemplo, un patrimonio artístico o cultural con toda la intensidad sin afirmar que el monumento o la obra artística en cuestión sean titulares de ningún derecho subjetivo.

Respondiendo a ello desde posturas favorables a los derechos de los animales se ha alegado que una obra de arte no posee ningún interés propio, sino que son las personas o la humanidad en su conjunto quienes están interesadas en su existencia y por ese motivo le otorgan una protección jurídica. Los animales, en cambio, sí poseen, como hemos visto, intereses propios en mayor o menor intensidad dependiendo de cada especie. Están ellos mismos interesados en su propia existencia o, al menos, en su existencia libre de sufrimiento. En consecuencia, en ese sentido parece más razonable hablar de que poseen derechos que considerarlos simplemente bienes jurídicos a proteger. Otro contraargumento, menos refinado este, sería el que alega que, al reducirse la protección de los animales a la categoría de bienes jurídicos protegidos, estos cederían siempre frente a los derechos, que parecen ser un grado de protección jurídica superior. Esta afirmación, sin embargo, carece de un fundamento sólido: baste pensar en las múltiples ocasiones en que los tribunales, tras realizar una ponderación, han determinado que cierto derecho subjetivo debe ceder ante tal o cual interés jurídico protegido.

\section{Argumento 5: la funcionalidad del Derecho}

En relación con ello, un quinto argumento contrario a hablar de derechos de los animales podría apelar a consideraciones funcionales del Derecho. El punto de partida es la consideración del Derecho principalmente como una herramienta de control del comportamiento humano en sociedad. El lenguaje de los derechos es un lenguaje eminentemente jurídico y, en consecuencia, un lenguaje eminentemente humano. Como tal, requiere una capacidad de entendimiento en cierta medida avanzada, exige compartir un mismo universo lingüístico y epistemológico que, hasta donde sabemos, los animales no están en condiciones de compartir con nosotros. Del mismo modo que nosotros no gozamos de tantas maravillosas características de las que los animales 
disfrutan, los animales parecen carecer de esa capacidad potencial para entender el funcionamiento de un orden normativo (llámese Derecho, moral o religión) que poseemos los humanos. Hablo de capacidad potencial porque efectivamente no es una capacidad con la que cuenten todos los humanos: pueden no haberla adquirido aún (niños) o pueden haberla perdido (enfermos mentales, personas en coma, etc.). A nadie le extrañaría, por ejemplo, ver a una paloma bebiendo de una fuente presidida por un cartel que anuncia "prohibido beber". La paloma parece reírse del Derecho por ser un sistema que no le afecta. Por este motivo, Kelsen, al hablar del Derecho como técnica social, afirma que "sólo el hombre, dotado de razón y voluntad, puede ser motivado por la representación de una conducta conforme a la norma"; y califica de primitivos los órdenes jurídicos que "dirigen consecuencias jurídicas no sólo contra hombres, sino también contra animales y cosas, tratando por tanto de regular también la conducta de sujetos no humanos" 20 .

Sobre ello el francés Luc Ferry ha narrado de forma jocosa algunas causas contra animales $^{21}$ llevadas a cabo ante los tribunales eclesiásticos durante la edad media. Según documenta Ferry, entre los siglos XIII y XVIII se practicaron por toda Europa docenas de juicios contra animales. Aves, ratas, sanguijuelas o delfines eran citados a juicio siguiendo todas las formalidades del Derecho romano. Si no comparecían, cosa que sucedía bastante frecuentemente, eran declarados en rebeldía y se procedía a realizar el juicio en su ausencia, asignándoseles debidamente abogado y procurador. En la mayoría de casos los animales eran condenados a pena de excomunión. La situación, por grotesca, recuerda al "requerimiento" practicado a partir del siglo XVI por los colonos españoles a los nativos americanos, tan precisamente descrito, si bien en sentidos contrarios, por Bartolomé de las $\operatorname{Casas}^{22}$ y por Gonzalo Fernández de Oviedo.

El Derecho no cumple su función si no es comprendido, porque no puede entonces motivar la conducta de los sujetos, que es su fin principal. Sin ese universo de significado compartido, parece difícil que la lógica del Derecho, y con ella la lógica de los derechos, encaje demasiado bien en el mundo animal. Esta afirmación, sin embargo,

\footnotetext{
${ }^{20}$ Vid. H. KELSEN, Teoría Pura... cit., pp. 56-57.

${ }^{21}$ FERRY, L., El nuevo orden ecológico. El árbol, el animal y el hombre, Tusquets, Barcelona, 1994, p. 11 y ss.

${ }^{22}$ Vid. DE LAS CASAS, B., Brevísima relación de la destrucción de las Indias, Biblioteca Virtual Miguel de

$<$ http://www.cervantesvirtual.com/servlet/SirveObras/12479514321225063632457/index.htm>.

Cervantes,
} 
no equivale a negar que los animales puedan tener pensamiento o lenguaje; ni siquiera equivale a afirmar que su pensamiento o su lenguaje sean inferiores a los nuestros. Dado el estado actual del conocimiento en este ámbito, cualquier afirmación en sentido contrario solo podría ser resultado de un prejuicio, como agudamente ha destacado Pocar $^{23}$.

De igual forma, si consideramos que la esencia del Derecho consiste en ser un sistema basado en la resolución de forma pacífica de los conflictos que se dan entre las partes, sometiendo a un tercero imparcial supra partes su resolución, este esquema no parece aplicable al reino animal, en cuyo ámbito se intuye cuanto menos difícil la inevitabilidad de los conflictos entre animales y más aún su resolución de forma pacífica. Por otro lado, el enfoque contractualista, según ha analizado Nussbaum ${ }^{24}$, presenta numerosas carencias para acercarse al problema de los derechos de los animales. Entre ellas, por ejemplo, que en este caso se incumpliría la condición rawlsiana de que ninguna de las partes que suscriben el contrato social sea lo suficientemente poderosa como para dominar unilateralmente a todas las demás.

\section{Argumento 6: la teoría de los círculos concéntricos}

El último argumento a analizar es el que formula la siguiente legítima pregunta: ¿acaso podemos ocuparnos del bienestar del resto de especies sin tener siquiera garantizado el de la nuestra propia? Viendo el estado en el que se encuentran los derechos humanos en el mundo, ¿no es preferible ocuparnos primero de resolver los problemas que afectan a los nuestros ${ }^{25}$ ? Esta cuestión admite múltiples respuestas, pero me conformaré con señalar tres. La primera podría ser que esa lógica, si fuera aplicada en serio, llevaría al completo egoísmo. Pensemos qué sería del mundo si nunca se hiciera nada por los demás, por aquellos que no son como nosotros, especialmente por aquellos que son más débiles o que no pueden defenderse por sí mismos. No se habrían conseguido avances tan sustanciales en derechos humanos como la Convención sobre los Derechos del Niño de 1989 o la Convención sobre los Derechos de las Personas con Discapacidad de 2006.

\footnotetext{
${ }^{23}$ POCAR, V., "Derechos de los animales y derechos humanos", en Teoría y Derecho, núm. 6, 2009, pp. 20-28.

${ }^{24}$ NUSSBAUM, M., Las fronteras de la justicia... cit., p. 325 y ss.

${ }^{25}$ Sobre la réplica a este argumento, vid. POGGE, Th., La pobreza en el mundo y los derechos humanos, Paidós, Barcelona, 2005; particularmente el capítulo titulado "Las fronteras del nacionalismo", pp. 155188
} 
En segundo lugar, como ha destacado nuevamente Pocar $^{26}$, cuando se habla de derechos, el aplazar su reconocimiento equivale simplemente a su negación. Si la consecuencia de ese aplazamiento es el sufrimiento continuado que millones de individuos animales están padeciendo en la actualidad, parece que ese aplazamiento no es demasiado coherente con un mínimo sentido de la justicia.

$\mathrm{Y}$ en tercer lugar, podemos afirmar que existe una interdependencia no solo entre los derechos humanos, sino también entre los derechos humanos y los derechos de los animales. Compartimos un único planeta, estamos en el mismo barco; de modo que mejorar las condiciones en las que viven los animales repercutirá en la mejora de vida de los humanos, y viceversa. Ya Bobbio, en su famoso escrito La era de los derechos (1990), imaginando un optimista futuro para los derechos humanos, pensó en la extensión de los derechos "a nuevos sujetos, por ejemplo, los animales, que la moral común ha considerado siempre meros objetos o, como mucho, sujetos pasivos carentes de derechos" $" 27$.

Antes de realizar precisamente algunas propuestas de convivencia en ese sentido, espero que el repaso a este parcial argumentario haya servido para mostrar que el hecho de usar el lenguaje de los derechos para proteger más y mejor los intereses de los animales no es una cuestión pacífica; sin embargo, desde el punto de vista de la teoría del Derecho no habría mayores inconvenientes para poder hacerlo. No habría demasiados obstáculos a priori para que los animales pudieran ser titulares de derechos en la misma medida en la que son titulares las personas; es decir, de acuerdo con sus necesidades. Otro asunto sería justificar que la lógica de los derechos subjetivos sea la única vía adecuada para garantizar la protección de los intereses animales. Nada nos obliga a reducir todo el universo de relaciones que se pueden producir entre el ser humano y los animales a la categoría de derechos, sino que pueden existir otras fórmulas mucho más ricas y acertadas que todavía están por inventar. En este sentido, resultan interesantísimas las ideas que recientemente han lanzado Donaldson y Kymlicka, que proponen la superación de muchos de los postulados de las teorías animalistas para proponer una

\footnotetext{
${ }^{26}$ POCAR, V., "Derechos de los animales y...”, cit., p. 21.

${ }^{27}$ BOBBIO, N., "La era de los derechos", en El problema de la guerra y las vías de la paz, Gedisa, Barcelona, 1982, p. 171.
} 
nueva dimensión política de la convivencia entre animales y humanos ${ }^{28}$. Por eso mismo, si decidimos utilizar el lenguaje de los derechos, como ha expresado De Lucas, el problema fundamental no es una cuestión de técnica jurídica, sino, como siempre que se habla de derechos, una cuestión política ${ }^{29}$. Una cuestión política, cabe decir, notablemente más influida en este caso que en otros por nuestros condicionamientos culturales.

\section{DOS PROPUESTAS DE CONVIVENCIA GARANTISTA}

En esta última parte esbozaré dos propuestas de convivencia garantista, una de carácter más general y otra más concreta, basadas en la interdependencia de los derechos entre especies. Antes de hacerlo, he de confesar que hablar de derechos de los animales me sigue planteando al menos un interrogante ligado con lo que creo que es una carencia justificativa. Básicamente, ¿por qué solo derechos para los animales? Si el objetivo es que nuestras consideraciones morales vayan más allá del ámbito de lo humano, ¿por qué limitarlas al ámbito de los animales?, ¿por qué no extenderlas al conjunto de la naturaleza? ¿No nos estaremos centrando en determinadas características compartidas (como la capacidad de sentir) entre los seres humanos y los animales que indican que no hemos abandonado del todo el antropocentrismo? Quizá si queremos salir realmente del antropocentrismo no solo tenemos la obligación moral (en el futuro tal vez jurídica) de respetar a los seres que tengan una vida parecida a la nuestra (animales), sino también a aquellos más diferentes (como las plantas) e incluso, ¿por qué no?, a las cosas sin vida pero que tuvieran algún valor natural, considerándolas como un bien en sí mismas. Es destacable en este sentido el reconocimiento de los derechos a la naturaleza o Pacha Mama que ha realizado la reciente Constitución ecuatoriana de 2008. Con todo un capítulo, el VII, dedicado a los derechos de la naturaleza, se proclaman derechos tan novedosos como el derecho de la Pacha Mama "a que se respete integralmente su existencia y el mantenimiento y regeneración de sus ciclos vitales, estructura, funciones y procesos evolutivos" (art. 71) o a la restauración de los sistemas naturales afectados (art. 72).

\footnotetext{
${ }^{28}$ Vid. DONALDSON, S. y KYMLICKA, W., Zoopolis. A Political Theory of Animal Rights, Oxford University Press, 2011.

${ }^{29}$ DE LUCAS, J., “En el bicentenario de Darwin...”, cit., p. 9.
} 


\section{Propuesta de desarrollo de la teoría garantista}

En el paradigma del Estado constitucional, la función del Derecho ya no es únicamente determinar las conductas mediante la coacción, sino que también presenta una evidente función protectora. El Derecho se convierte, como lo ha llamado Ferrajoli, en la ley del más débil ${ }^{30}$. Desde el prisma garantista, que se basa en el establecimiento de una serie de controles y vínculos al poder en el sentido fuerte, una de las principales funciones del Derecho es proteger, y no existen motivos jurídicos por los que deba limitarse a proteger solamente a las personas, sino que potencialmente podría tender a proteger también a los animales e incluso al planeta en su conjunto respecto de las acciones humanas - las cuales se han demostrado dramáticamente devastadoras, especialmente con la evolución en los dos últimos siglos de la economía capitalista, basada, por definición, en un crecimiento ilimitado-.

Ferrajoli ha previsto tres extensiones del paradigma garantista ${ }^{31}$. Como conjunto de límites y vínculos que sujetan al poder, el paradigma garantista de Derecho: 1) no solo se debe limitar a controlar a los poderes públicos, sino que también debe extenderse al control de los poderes privados; 2) no solamente se debe referir a garantizar los derechos políticos y civiles, sino que también debe ser extendido a la garantía de los derechos económicos y sociales; y 3) no únicamente debe limitarse al ámbito nacional, sino que también debe extenderse al ámbito internacional. Junto a estos tres desarrollos, debería comenzar a pensarse en un cuarto desarrollo que implicase que el conjunto de límites al poder impuestos por el paradigma garantista no se limite únicamente al ámbito de la protección de lo humano, sino que se extienda tendencialmente a salvaguardar también el conjunto de la naturaleza. El potencial protector del Derecho debe extenderse de esa manera a los otros seres vivos y al planeta en su conjunto.

Al fin y al cabo, de lo que se trata es de pensar si hemos superado la ley de la selva, en la que el pez grande se come al pez chico, en la que el fuerte siempre se impone al débil. Si la construcción del Estado constitucional de derecho ha servido, precisamente, para proteger al débil del fuerte, a las minorías de las mayorías, ¿por qué no extender esta dinámica garantista al conjunto de especies que conviven con nosotros?, ¿por qué no extenderla al conjunto de la naturaleza? Ante la grave crisis ecológica que se avecina, si

\footnotetext{
${ }^{30}$ FERRAJOLI, L., Derechos y garantías. La ley del más débil, Trotta, Madrid, 2006.

${ }^{31}$ FERRAJOLI, L., Democracia y garantismo, edición de Carbonell, M., Trotta, Madrid, 2008, pp. 267 y SS.
} 
el Derecho quiere cumplir realmente su función protectora, debe aproximar su mirada a las ciencias naturales y particularmente a la ecología. De la conexión entre disciplinas han surgido frecuentemente las soluciones más interesantes, como la teoría del decrecimiento, que parte de la aplicación que el matemático y economista rumano Georgescu-Roegen realizó de la física, concretamente de la segunda ley de la termodinámica o ley de la entropía, a la ciencia económica ${ }^{32}$.

\section{Propuesta de modelo alimentario}

La propuesta de carácter general relacionada con la extensión del garantismo seguramente podrá apreciarse con más claridad si es relacionada con una propuesta de aplicación concreta en la que puedan interaccionar derechos humanos y derechos de los animales. Esta propuesta concreta tiene que ver con la alimentación humana y particularmente con el consumo de carne animal o zoofagia. Los hábitos alimentarios de Occidente, excesivamente basados en el consumo de carne, provocan un claro problema de justicia que afecta tanto a la especie humana como a múltiples especies del reino animal.

Si evitar el sufrimiento animal causado por las acciones humanas es un objetivo moralmente deseable, sabemos que existen innumerables prácticas que causan ese sufrimiento: la experimentación en los laboratorios, fiestas populares que podemos llamar primitivas, la peletería, etc. Pero, sin duda, cuantitativamente la principal fuente de sufrimiento animal es el sustento del sistema alimentario mundial, que día tras día produce (o, mejor, fuerza el nacimiento de) millones de individuos animales cuya única expectativa vital es ser consumidos por sujetos de la especie humana. Las condiciones generadoras de dolor y sufrimiento a las que estos animales son sometidos en la inmensa mayoría de explotaciones agropecuarias han sido sobradamente demostradas por el trabajo de múltiples asociaciones de la sociedad civil $^{33}$.

La situación respecto a la especie humana también dista de poder considerarse justa. Según la Organización de Naciones Unidas para la Agricultura y la Alimentación (FAO), a finales de 2009 existían en el mundo 1.020 millones de personas en situación

\footnotetext{
32 Vid. GEORGESCU-ROEGEN, N., La ley de la entropía y el proceso económico, Fundación Argentaria-Visor, Madrid, 1996 [1971].

${ }^{33}$ Por citar dos de las organizaciones que hacen un destacado trabajo en el Estado español en este ámbito, pueden mencionarse igualdadanimal.org o defensanimal.org.
} 
de desnutrición. Una de cada seis personas del planeta no tiene qué comer. Por el contrario, al mismo tiempo 1.750 millones de personas sufren de sobrepeso ${ }^{34}$. Estos dos simples datos pretenden ilustrar una situación caracterizada por un profundo desequilibrio y por una creciente inequidad. Nunca antes había habido tantas personas pasando hambre en el mundo y, al mismo tiempo, nunca había habido tantas personas obesas y con problemas cardiovasculares derivados.

Nuestros hábitos alimenticios excesivamente basados en el consumo de carne, además de ser fuente de problemas de salud ${ }^{35}$, son fuente de injusticia. Y no solamente son fuente de injusticia respecto de nuestra especie, sino también respecto a las especies animales. Es un problema que refleja una profunda interdependencia. Según el Programa de Naciones Unidas para el Medio Ambiente ${ }^{36}$, los requerimientos calóricos para el engorde del ganado representan el consumo calórico de 3.500 millones de personas — la mitad de la población mundial—. El 40\% del grano que se cosecha hoy a escala global se destina al engorde del ganado, al que se dedican, en un planeta de cada vez más escasos recursos, 47 millones de hectáreas sembradas con forraje ${ }^{37}$. La pregunta, entonces, podría ser: ¿es sostenible que coman las personas y que coma el ganado (todo el ganado que existe para dar satisfacción a la dieta carnívora occidental)? La respuesta se convierte en una cuestión de reparto global: simplemente no hay territorio suficiente para cultivar pastos con los que alimentar a la población de vacas (una población de vacas artificialmente inflada por la mano humana) y a la vez para cultivar cereales o productos que alimenten directamente a las personas.

Por ese motivo, aplicado al caso concreto del modelo alimentario en cuestión, el cuarto desarrollo del paradigma garantista aquí simplemente apuntado pretende ser una propuesta de convivencia entre humanos y entre animales articulada en torno a diferentes modificaciones jurídicas de hondo calado.

La principal de esas modificaciones tendría que ver con la sujeción no solo de los poderes públicos, sino también de los poderes privados (que es el primero de los desarrollos del modelo garantista). Es significativo el gran poder alcanzado por la

\footnotetext{
${ }^{34}$ Según datos recogidos del International Obesity Task Force (www.iotf.org).

${ }^{35}$ Vid., por ejemplo, RAMONET, I., "La gran amenaza del virus A(H1N1): Mucho más que una gripe", en Le Monde diplomatique, núm. 164, junio 2009.

${ }^{36}<$ www.unep.org $>$.

${ }^{37}$ DUCH, G., “¿Cómo nos alimentamos?”, en Público, 15 de febrero 2010.
} 
industria cárnica, que mueve miles de millones de dólares anualmente. Sin embargo, el hecho de que la carne sea un negocio lucrativo para unas pocas personas no puede justificar el sufrimiento diario de millones de individuos animales ni tampoco las graves consecuencias sociales y medioambientales ${ }^{38}$ que implica. La mejor protección de los derechos humanos y la perspectiva de que los animales puedan obtener derechos deben pasar necesariamente por un fortalecimiento de los controles del mercado y, más aún, por una limitación de los ítems que se pueden intercambiar a través de él. Proteger derechos es siempre, en cierta medida, desmercantilizar, es decir, sacar del comercio.

En este sentido, es oportunísima la tesis sostenida por Gary L. Francione ${ }^{39}$, que mantiene que si algún derecho deben tener los animales, este es el derecho a no ser tratados como una propiedad. Si los animales no pudieran ser propiedad de nadie, no podrían ser comerciados. De nuevo podemos tomar un ejemplo del Código Civil español, cuyo artículo 610, en el libro que regula los modos de adquirir la propiedad, equipara los animales a las cosas (“Se adquieren por la ocupación los bienes apropiables por su naturaleza que carecen de dueño, como los animales que son objeto de la caza y pesca, el tesoro oculto y las cosas muebles abandonadas"). Si se acepta que los animales tienen unos intereses propios y que, consecuentemente, deben ser considerados pacientes morales, no parece demasiado adecuado equiparar su estatus jurídico al de las cosas inanimadas.

De momento, la propuesta de suprimir la propiedad y, por lo tanto, el comercio de los animales no puede ser algo más que tendencial, un ideal al que aspirar. Se trata de cambios profundos solo realizables de forma realista a largo plazo y que no podrán ser alcanzados sin el compromiso y las exigencias de la ciudadanía. Es responsabilidad de quienes poseen el conocimiento comenzar a sensibilizar al resto en ese cambio social. Este quizá podría empezar a fomentarse desde dos planos distintos. Un primer plano sería el individual, que comenzaría básicamente por pensar antes de comer. Analizar si es justo y sostenible aquello de lo que nos alimentamos diariamente. Con seguridad una dieta vegana, aunque exige un alto grado de reflexión y compromiso personal, es la única que puede cumplir esos criterios de justicia y sostenibilidad. El segundo plano

\footnotetext{
${ }^{38}$ La FAO estima que la producción de carne es responsable de casi una quinta parte de las emisiones de gases de efecto invernadero. Por su parte, Rajendra Pachauri, presidente del Panel de Expertos del Cambio Climático de Naciones Unidas (IPCC), ha recomendado "reducir el consumo de carne para luchar contra el cambio climático" (The Observer, 7 de septiembre 2008).

${ }^{39}$ FRANCIONE, G., “Animales, ¿propiedad o personas?”, en Teoría y Derecho, núm. 6, 2009, pp. 30-59.
} 
sería el colectivo y debería pasar por la exigencia de una reforma en profundidad del sistema alimentario mundial, con el establecimiento de instituciones internacionales democráticas y vinculantes (en relación con el tercero de los desarrollos del paradigma garantista). Para ello, es imprescindible la consolidación de una esfera pública mundial, de una ciudadanía global informada y organizada. La dificultad de estas empresas no debe ser motivo de desánimo, sino, por el contrario, un estímulo para implicarse en ellas.

La crisis ecológica a la que se enfrenta la humanidad (que no es sino una de las múltiples caras de una crisis sistémica, es decir, del sistema conocido como capitalismo o, si se quiere, neoliberalismo) nos ha hecho cobrar conciencia de que los humanos no somos los amos y señores del planeta. El uso de superficie de la tierra no pertenece en exclusiva a la especie humana, como afirmara Kant al defender el derecho a la hospitalidad universal ${ }^{40}$. Nuestro futuro depende del hecho de que seamos capaces de compartir el planeta en armonía con el resto de especies. Poco importa en última instancia que ello se haga únicamente de manera instrumental, esto es, calculando que esa mejora repercutirá con toda seguridad en el bienestar humano; o bien como un fin, esto es, considerando los intereses de los animales y de los ecosistemas como bienes en sí mismos. Sea como fuere, el hecho de reivindicar derechos para los animales no debe ser visto como una cuestión de zoofilia $^{41}$ ingenua, sino como la consecuencia de la tendencia hacia una verdadera justicia global. Como ha escrito Nussbaum, "el objetivo de la justicia global obliga a la inclusión de numerosas personas y grupos que no habían sido anteriormente incluidos como sujetos de justicia"42. Los animales son uno de esos grupos que hasta ahora la justicia había olvidado.

\footnotetext{
${ }^{40}$ KANT, I., "Sobre la paz perpetua" (1795), en KANT, I., Ensayos sobre la paz, el progreso y el ideal cosmopolita, Ed. Cátedra, Madrid, 2009, p. 158.

${ }^{41}$ Zoofilia en su sentido original de "amor a los animales" y no con las connotaciones sexuales que se le suelen atribuir al término.

${ }^{42}$ NUSSBAUM, M., Las fronteras de la justicia... op. cit., p. 398.
} 


\section{BIBLIOGRAFÍA}

AÑÓN ROIG, M. J., Necesidades y derechos: un ensayo de fundamentación, Centro de Estudios Constitucionales, Madrid, 1994.

AÑÓN ROIG, M. J. y DE LUCAS, J., "Necesidades, razones y derechos", en Doxa: cuadernos de filosofía del Derecho, núm. 7, 1990, pp. 55-82.

BENTHAM, J., Introduction to the Principles of Morals and Legislation, Adamant Media Corporation, 2005 [1781].

BOBBIO, N., El problema de la guerra y las vías de la paz, Gedisa, Barcelona, 1982.

DE LAS CASAS, B., Brevísima relación de la destrucción de las Indias, Biblioteca Virtual Miguel de Cervantes.

DE LORA, P., Justicia para los animales. La ética más allá de la humanidad, Alianza, Madrid, 2003.

DE LUCAS, J., “En el bicentenario de Darwin. ¿Derechos de los animales no humanos? La barrera de la dignidad", en Teoría y Derecho, núm. 6, 2009, pp. 6-19.

DONALDSON, S. y KYMLICKA, W., Zoopolis. A Political Theory of Animal Rights, Oxford University Press, 2011.

DUCH, G., “¿Cómo nos alimentamos?”, en Público, 15 de febrero 2010.

- Lo que hay que tragar. Minienciclopedia de política y alimentación, Libros del Lince, Barcelona, 2010.

FERRAJOLI, L., Derecho y razón. Teoría del garantismo penal, Trotta, Madrid, 2005 [1989].

— Los fundamentos de los derechos fundamentales, Trotta, Madrid, 2005.

— Derechos y garantías. La ley del más débil, Trotta, Madrid, 2006.

— Democracia y garantismo, edición de M. Carbonell, Trotta, Madrid, 2008.

FERRY, L., El nuevo orden ecológico. El árbol, el animal y el hombre, Tusquets, Barcelona, 1994.

FRANCIONE, G., “Animales, ¿propiedad o personas?”, en Teoría y Derecho, núm. 6, 2009, pp. 30-59. 
GEORGESCU-ROEGEN, N., La ley de la entropía y el proceso económico, Fundación Argentaria-Visor, Madrid, 1996 [1971].

KANT, I., "Sobre la paz perpetua", en KANT, I., Ensayos sobre la paz, el progreso y el ideal cosmopolita, prólogo de Manuel Garrido, Cátedra, Madrid, 2009, pp. 141-187.

KELSEN, H., Teoría General del Estado, Coyoacán, 2008 [1925].

- Teoría Pura del Derecho. Introducción a la problemática científica del Derecho $\left(1^{\mathrm{a}}\right.$ ed.), Losada, Buenos Aires, 1941 [1934].

MOSTERÍN, J., Los derechos de los animales, Debate, Madrid, 1995.

MOSTERÍN, J. y RIECHMANN, J., Animales y ciudadanos. Indagación sobre el lugar de los animales en la moral y el derecho de las sociedades industrializadas, Talasa, Madrid, 1995.

NUSSBAUM, M., Las fronteras de la justicia. Consideraciones sobre la exclusión, Paidós, Barcelona, 2007.

NUSSBAUM, M. y SUNSTEIN CASS, R. (eds.), Animal rights: Current Debates and New Directions, Oxford University Press, Oxford, 2004.

POCAR, V., "Derechos de los animales y derechos humanos", en Teoría y Derecho, núm. 6, 2009, pp. 20-28.

POGGE, Th., La pobreza en el mundo y los derechos humanos, Paidós, Barcelona, 2005.

RAMONET, I., "La gran amenaza del virus A(H1N1): Mucho más que una gripe”, en Le Monde diplomatique, núm. 164, junio 2009.

RAWLS, J., Teoría de la justicia, Fondo de Cultura Económica, México, 1995 [1971].

REGAN, T., The Case for Animal Rights, University of California Press, 2003 [1983].

SALT, H. S., Los derechos de los animales, Los Libros de la Catarata, Madrid, 1999 [1892].

SINGER, P., Liberación animal, Trotta, Madrid, 1999 [1975]. 